\title{
MUDANÇAS CONCEITUAL E DE MODALIDADE: IMPACTOS NA USABILIDADE DE JOGOS DIGITAIS
}

\author{
Fernanda Maria Pereira Freire, UNICAMP, ffreire@gmail.com \\ André Constantino da Silva, IFSP, andre.constantino@ifsp.edu.br \\ Carolina Fernandes dos Reis, UNICAMP, carolinaf_reis@yahoo.com.br
}

\section{RESUMO}

Este artigo discute, com base na análise da interação entre duas pessoas jogando damas por meio de tablet e tabuleiro, como (i) as diferenças entre as regras usadas pelo modelo conceitual da versão digital e as regras do modelo conceitual do jogador, construídas a partir de experiências prévias, e (ii) como as diferenças no modo de interação entre jogador/interface e jogador/tabuleiro, podem interferir no padrão interativo que se estabelece entre o jogador/interface, por meio da modalidade de toque e, consequentemente, como esses dois fatores podem impactar a usabilidade da versão digital do jogo de damas.

Palavras-chave: modelo conceitual, modalidade, usabilidade

\section{CONCEPTUAL AND MODALITY CHANGES: IMPACTS ON USABILITY OF DIGITAL GAMES}

\begin{abstract}
This article discusses, based on the analysis of the interaction between two people playing checkers with tablet and board, as (i) the differences between the rules used by the conceptual model of the digital version and the rules of the conceptual model of the player, built from previous experiences, and as (ii) differences in mode of interaction between player/interface and player/board may interfere on interactive pattern that is established between player/interface, through the touch modality and, consequently, as such these two factors may impact on the usability of the digital version of checkers.
\end{abstract}

Keywords: conceptual model, modality, usability

\section{INTRODUÇÃO}

O crescente uso de dispositivos móveis tem favorecido a disseminação de aplicativos de jogos de entretenimento que divertem, motivam e potencializam o desenvolvimento do raciocínio, de estratégias e de resolução de problemas, convocando o funcionamento integrado de diversos processos mentais superiores como a atenção, a percepção, a memória, o raciocínio, a linguagem (Vygotsky, 1991; Luria, 1979).

Muitos desses jogos, bastante conhecidos, são de tabuleiro e têm sido transpostos para funcionarem em dispositivos móveis. Mas, em que medida o modelo conceitual das versões digitais reproduzem ou alteram as regras que norteiam a interação do jogador com o jogo e/ou entre os jogadores? Em que medida a mudança do tipo de interação entre jogador e jogo - da interação física para a digital mediada por movimentos como tocar e arrastar - pode afetar o ato de jogar?

$\mathrm{Na}$ tentativa de responder a essas questões nosso estudo se propõe a analisar dados de interação entre dois jogadores utilizando uma versão do tradicional Jogo de Damas para o modelo de tablet Android Samsung e utilizando a versão em tabuleiro, com vistas a discutir os eventuais impactos que as mudanças de modelo conceitual e de modalidade de interação podem exercer sobre a usabilidade (Nielsen, 1993) do jogo digital. 
A escolha do Jogo de Damas se deve ao fato de ser amplamente conhecido em nossa cultura e, portanto, ter um modelo conceitual bem estabelecido, construído com base em sua versão física. Nossa suposição é a de que o entendimento do modo como um jogo é transposto para o ambiente digital pode auxiliar o design de jogos digitais, incluindo os com finalidades educativas que, diferentemente do que ocorre com o Jogo de Damas para a maioria das pessoas, requer que o usuário compreenda a proposta de seu modelo conceitual com pouco esforço cognitivo, o que pode ser beneficiado por uma interface com boa usabilidade e em conformidade com a(s) modalidade(s) do(s) dispositivo(s) que a suporta (Silva, 2014).

Segundo Nielsen (1993), a usabilidade tem a ver com o fato de um software poder ser usado com eficiência, ser fácil de ser aprendido e lembrado, apresentar baixa incidência de erros do usuário e ser usado com satisfação por usuários específicos para atingir certos objetivos em um contexto específico. O modelo conceitual, por sua vez, é definido por Johnson e Henderson (2002) como uma descrição de alto nível de como um sistema é organizado e é operado, o que abrange: as principais metáforas e analogias usadas no design da sua interface; os conceitos que o sistema expõe ao usuário, incluindo as tarefas do domínio e os objetos-dados, seus atributos e suas operações; as relações entre esses conceitos; os mapeamentos entre os conceitos e as tarefas do domínio para o qual o sistema é projetado. A descrição dos elementos e das regras de um jogo expõe seus objetos, a relação entre esses objetos e as operações sobre esses objetos revelando, portanto, uma parte do seu modelo conceitual.

No caso do Jogo de Damas, duas pessoas interagem usando um tabuleiro de 64 casas alternadas entre claras e escuras, com 12 peças brancas e 12 pretas distribuídas para cada jogador e posicionadas nas casas escuras, ocupando as três linhas inferiores do tabuleiro, mais próximas de cada jogador. As jogadas se alternam entre os jogadores e as peças comuns só podem se movimentar para frente, isto é, para uma casa escura livre na próxima linha, diagonal à casa onde se encontra; enquanto as "damas", peças que atingem a última linha do tabuleiro do adversário, representadas pela sobreposição de duas peças, podem ser movimentadas em grandes diagonais para frente e para trás, para qualquer casa livre. O objetivo do jogo é capturar todas as peças do oponente ou deixá-lo impossibilitado de mover suas peças quando, então, encerra-se o jogo. Os torneios oficiais de Damas preveem como regra obrigatória a subtração de uma peça do adversário em posição de captura. Informalmente, no entanto, os adversários podem adotar, em comum acordo, o chamado "sopro" que estipula que um jogador pode subtrair uma peça do seu adversário quando este não perceber a existência de uma peça em posição de captura, penalizando o jogador desatento. A depender de qual regra é adotada, haverá uma diferença no modelo conceitual criado, pois as operações possíveis sobre um objeto fazem parte do modelo conceitual do sistema.

Neste estudo, partimos do pressuposto de que um jogo em dupla é uma atividade que integra dois níveis de interação relacionados: (i) entre os jogadores, mediada pela linguagem e o ato de jogar e (ii) entre cada um dos jogadores e o próprio jogo, mediada pela interface do aplicativo ou pelo tabuleiro (Freire, 2006). No caso de um jogo digital a interação entre o jogador e o sistema segue um determinado padrão interativo, representado por ações dirigidas a objetivos que são executadas pelo jogador e pelo sistema e que, no caso do jogador, se dão de acordo com determinado modo de interação, dependente do tipo de dispositivo que suporta a aplicação. O modo de interação ou modalidade, conforme Alty e McCartney (1991) definem, tem a ver com a maneira como uma entrada do usuário e uma saída do sistema são expressas. No caso do nosso estudo, a interação se dá por meio da modalidade de toque, uma sequência de movimentos que tende a se automatizar pela repetição com sentido (Luria, 1979). Nossa 
suposição é a de que uma ruptura nesse padrão interativo, seja pela seleção de uma ação não adequada ao contexto, seja pela realização não adequada de movimentos, pode ser indicativa de problemas de usabilidade.

Neste artigo nosso objetivo é discutir, com base na análise da interação entre duas pessoas jogando Damas por meio de um tablet e usando a versão em tabuleiro, como (i) as diferenças entre as regras usadas pelo modelo conceitual da versão digital e as regras do modelo conceitual do jogador, construído com base em sua experiência prévia, bem como (ii) as diferenças no modo de interação entre jogador e interface e jogador e tabuleiro, ambos decorrentes da transposição do jogo do ambiente real para o digital, podem interferir na manutenção do padrão interativo entre jogador e sistema e, assim, impactar a usabilidade do Damas em sua versão digital (DD).

\section{METODOLOGIA}

Do ponto de vista metodológico o estudo está organizado em duas fases denominadas Fases 1 e 2. Na primeira fase realizamos pré-testes com a versão digital do Jogo de Damas com o objetivo de verificar o seu funcionamento no tablet, bem como (re)conhecer o seu modelo conceitual e o seu modelo de interação. Na segunda fase organizamos e realizamos um estudo de caso envolvendo dois voluntários brincando de Damas usando o tablet e o tabuleiro. Antes, porém, fizemos uma entrevista informal com ambos com o intuito de levantar o perfil de cada um deles.

Os pré-testes do Jogo de Damas Digital (DD) foi realizado por um usuário, CR, de 19 anos; sexo feminino; com bom conhecimento sobre computadores, jogos e dispositivos móveis; com formação técnica em informática. CR utilizou o jogo em sua versão default tendo como adversário o tablet com o objetivo de verificar seu funcionamento, conhecer o modelo conceitual adotado pelos desenvolvedores e verificar o modelo de interação. O aplicativo usado foi desenvolvido pela Magma Mobile para o sistema operacional Android e traz algumas opções de configuração: alterar a cor das peças; escolher o grau de dificuldade (iniciante, fácil, médio, difícil, mestre); escolher o computador como adversário; escolher qual jogador inicia a partida.

$\mathrm{Na}$ Fase 2 realizamos o estudo de caso do qual participaram dois voluntários, um adulto e um pré-adolescente, ambos conhecedores do Jogo de Damas em tabuleiro ${ }^{1}$. Os dois voluntários responderam, informalmente, a um conjunto de questões que mostram a familiaridade que ambos têm com dispositivos móveis e com o Jogo de Damas, como mostra a Tabela 1.

Tabela 1 - Perfil dos voluntários

\begin{tabular}{|l|l|l|}
\hline \multicolumn{1}{|c|}{ Perguntas } & \multicolumn{1}{|c|}{ Jogador_1: FF } & \multicolumn{1}{c|}{ Jogador_2: MC } \\
\hline Idade & 53 anos & 13 anos \\
\hline Gênero & Feminino & Masculino \\
\hline Já jogou damas? & Sim & Sim \\
\hline Com quem joga? & Filhos e amigos & Contra o computador \\
\hline $\begin{array}{l}\text { Joga em celular ou } \\
\text { tablet? }\end{array}$ & Só durante o experimento & Sim, em celular Android \\
\hline E em computador? & Não & Sim \\
\hline $\begin{array}{l}\text { Costuma usar bastante } \\
\text { o tablet? Para que? }\end{array}$ & Não & $\begin{array}{l}\text { Sim, para acessar o Facebook, } \\
\text { o Google e, às vezes o Word }\end{array}$ \\
\hline $\begin{array}{l}\text { Como costuma jogar } \\
\text { damas, isto é, que } \\
\text { regras utiliza? }\end{array}$ & $\begin{array}{l}\text { FF descreve o } \\
\text { funcionamento do jogo e - } \\
\text { "peças andam na diagonal } \\
\text { casa a casa; exceto quando é } \\
\text { dama"; "ganha quem } \\
\text { subtrair o maior número de } \\
\text { peças do adversário", mas } \\
\text { não menciona nenhuma } \\
\text { regra específica. }\end{array}$ & $\begin{array}{l}\text { MC descreve o funcionamento do jogo e cita três } \\
\text { regrano per que seja uma } \\
\text { tama; (ii) poder capturar peças } \\
\text { em sequência; (iii) o "sopro" }\end{array}$ \\
\hline
\end{tabular}

A interação entre os voluntários jogando as duas versões de Damas (digital e tabuleiro) foi gravada em vídeo e, posteriormente, transcrita usando a tabela do BDN - 
Banco de Dados em Neurolinguística ${ }^{2}$. Originalmente, o BDN contava com cinco colunas que foram, pouco a pouco sendo modificadas, em função das especificidades de diferentes situações interativas, visando retratar cada dinâmica para dar visibilidade ao que pode ser relevante para as pesquisas que o utilizam como procedimento metodológico (Coudry, 2003). Estudos que envolvem interações mediadas por dispositivos (computadores, tablets, celulares) motivaram a inclusão de uma coluna para mostrar o funcionamento do sistema/interface em resposta às ações do usuário (Freire, 2004; 2005). Assim, a versão do BDN utilizada tem seis colunas: Linha (facilita a identificação e a referência a um determinado momento da interação), Jogador (identifica as pessoas envolvidas nesta interação particular), Ação (descreve o que cada jogador faz), Interface (descreve o comportamento do sistema), Enunciados orais (apresenta as falas dos jogadores) e Observações (anotações do pesquisador sobre o que ocorre na interação).

\section{ANÁLISE DE DADOS E DISCUSSÃO}

Durante a fase de pré-testes (Fase 1) foi possível observar fatores relacionados a: (i) fenômenos decorrentes da mudança de modalidade do jogo (tabuleiro x versão digital) e (ii) diferenças em relação ao modelo conceitual adotado pelo aplicativo e o jogo de tabuleiro. Em relação à mudança de modalidade, tomando como parâmetro os movimentos que os jogadores usam para jogar Damas em tabuleiro para deslocar uma peça - pegar a peça, arrastá-la sobre o tabuleiro, deixar a peça sobre a casa desejada observamos que o DD torna discreto esse movimento contínuo (pegar, arrastar, soltar), mapeando-o como dois toques, desconsiderando a possibilidade da modalidade do dispositivo de arrastar, o que aproximaria seu modelo de interação com aquele utilizado no jogo físico. Assim, a interação mais simples entre o jogador e o DD pode ser descrita como segue na Tabela 2.

Tabela 2 - Padrão simples de interação entre jogador e DD

\begin{tabular}{|l|l|}
\hline Ações do Jogador & Accões do Sistema \\
\hline (Ação_J_1): jogador toca na peça & $\begin{array}{l}\text { (Ação_S_1): iluminam-se as casas do } \\
\text { tabuleiro disponiveis para a } \\
\text { movimentação da peça selecionada }\end{array}$ \\
\hline $\begin{array}{l}\text { (Ação_J_2): jogador toca em uma das } \\
\text { casas iluminadas pelo sistema }\end{array}$ & $\begin{array}{l}\text { (Ação_S_2): a peça é movida para casa } \\
\text { selecionada }\end{array}$ \\
\hline
\end{tabular}

As ações do sistema podem se tornar mais complexas (Tabela 3), a depender do posicionamento da peça no tabuleiro, ocasião em que o sistema pode encadear suas ações como uma ação única, como no caso da captura de peças em sequência ou a formação de uma dama.

Tabela 3 - Padrão complexo de ações do sistema

\begin{tabular}{|l|l|}
\hline Posição da(s) peça(s) no tabuleiro & Ações do Sistema \\
\hline $\begin{array}{l}\text { Uma peça do adversário está em posição de captura e o jogador } \\
\text { a captura }\end{array}$ & $\begin{array}{l}\text { (Ação_S_3): a peça do adversário é capturada ao mesmo } \\
\text { tempo em que a peça do jogador aparece na casa tocada } \\
\text { pelo jogador }\end{array}$ \\
\hline $\begin{array}{l}\text { Uma peça do adversário está em posição de captura, mas o } \\
\text { jogador não percebe/vê }\end{array}$ & $\begin{array}{l}\text { (Ação_S_4): sistema ilumina a casa de uma peça que está } \\
\text { em posição de captura (para alertar o jogador da } \\
\text { obrigatoriedade de captura) }\end{array}$ \\
\hline $\begin{array}{l}\text { Duas ou mais peças do adversário estão em posição de captura } \\
\text { e o jogador as captura }\end{array}$ & $\begin{array}{l}\text { (Ação_S_5): sistema captura duas (ou mais) peças que se } \\
\text { encontram dispostas de tal forma que podem ser } \\
\text { capturadas sequencialmente }\end{array}$ \\
\hline $\begin{array}{l}\text { Jogador capturou uma peça e chegou à última linha do tabuleiro } \\
\text { do adversário }\end{array}$ & $\begin{array}{l}\text { (Ação_S_6): sistema faz uma animação e sobrepões uma } \\
\text { peça a outra para compor uma dama }\end{array}$ \\
\hline
\end{tabular}

Diferenciamos o padrão de interação simples do complexo com o intuito de chamar a atenção para o número de eventos que ocorrem quase simultaneamente na interface 
quando se trata de uma ação complexa do sistema e que pode, a depender da familiaridade do jogador com jogos digitais, sobrecarregar sua percepção e interpretação do feedback.

Em relação às regras do modelo conceitual, chama atenção a diferença que há entre as regras adotadas pelo DD e as reportadas pelo Jogador_2 (MC), um dos voluntários do estudo de caso, por ocasião da entrevista que fizemos para levantamento do seu perfil (cf. Tabela 1). A transposição do jogo de tabuleiro para o ambiente digital assume como default as regras que orientam torneios oficiais de Damas, ao passo que, explicitamente, o Jogador_2 (MC) utilizar o "sopro" como regra, embora tenha familiaridade com versões digitais do jogo (Tabela 4).

Tabela 4 - Modelo conceitual de DD e do jogo de tabuleiro

\begin{tabular}{|l|c|l|}
\hline \multicolumn{1}{|c|}{ Modelo Conceitual } & DD & \multicolumn{1}{|c|}{ Tabuleiro } \\
\hline Obrigatoriedade de captura (default) & Sim & $\begin{array}{l}\text { Depende do jogador ou de acordo } \\
\text { entre eles }\end{array}$ \\
\hline $\begin{array}{l}\text { Possibilidade de alteração e } \\
\text { personalização de regras }\end{array}$ & Sim & Não \\
\hline Possibilidade de desfazer jogadas & Sim & Depende de acordo entre os jogadores \\
\hline
\end{tabular}

A obrigatoriedade de captura da peça do adversário é mostrada pela interface de DD por meio de uma ação específica, Ação_S_4 (cf. Tabela 3), que ilumina a peça do jogador que está próxima a uma peça do oponente em posição de captura.

Como já foi dito, na Fase 2, realizamos um estudo de caso do qual participaram os Jogadores_1 (FF) e Jogador_2 (MC), cujos perfis foram apresentados na Tabela 1. Em um mesmo dia os voluntários jogaram Damas no tablet e, em seguida, no tabuleiro. Registramos as duas interações em vídeo para posterior transcrição. O jogo no tablet durou cerca de 5 minutos, resultando em 124 linhas de transcrição do BDN; a partida em tabuleiro durou cerca de 11 minutos, mais que o dobro da anterior, o que mostra o dinamismo dos jogos digitais, correspondendo a 94 linhas de transcrição.

Nossa análise busca indícios de quebra do padrão de interação com a interface do jogo, com base na hipótese de que esse fenômeno possa indicar potenciais problemas de usabilidade. Assim, identificamos dois tipos de quebra, Dados 1 e 2, provocados pela diferença entre as regras do modelo conceitual de DD e as usadas pelo jogador e pela mudança de modalidade, respectivamente.

\subsection{Dados 1 e 2: Análise da interação por meio do Damas Digital}

Essa partida é iniciada pelo Jogador_2 (MC), mais experiente em jogar Damas usando computadores e tablets, o que, provavelmente contribuiu para interagir de imediato de forma adequada com a interface (toca a peça e toca a casa). O Jogador_1 (FF), em seguida, segue esse mesmo padrão de interação.

No momento em que o Dado 1 (Tabela 5) foi produzido (linhas 17 a 25 do BDN) o Jogador_2 (MC) tenta deslocar uma de suas peças, mas o sistema não responde a sua ação porque identifica a presença de uma peça do adversário em posição de captura. $\mathrm{O}$ sistema tenta alertar MC por meio da iluminação da sua peça que está próxima à peça do Jogador_1 (FF).

Na linha 17 MC (Jogador_2) tenta movimentar uma determinada peça, mas o sistema ilumina a casa de outra, diferente da que selecionou, na tentativa de alertá-lo sobre a existência de uma peça do oponente em posição de captura, uma vez que é obrigatório, segundo o modelo conceitual do jogo, subtrair peças que se encontram em posição de captura. 
Tabela 5 - Dado 1: Alerta de captura

\begin{tabular}{|c|c|c|c|l|l|}
\hline L & J & Ações & Interface & \multicolumn{1}{|c|}{ Enunciados } & \multicolumn{1}{c|}{ Observações } \\
\hline 17 & MC & Ação_J_1 & Ação_S_4 & & $\begin{array}{l}\text { Sistema alerta o jogador sobre a } \\
\text { existência de uma peça do oponente } \\
\text { em posição de captura }\end{array}$ \\
\hline 18 & MC & Ação_J_1 & Ação_S_4 & & Idem \\
\hline 19 & MC & Ação_J_2 & Ação_S_4 & & Idem \\
\hline 20 & FF & & & $\begin{array}{l}\text { Sabe o que é? É obrigatório } \\
\text { comer. }\end{array}$ & $\begin{array}{l}\text { MC se dá conta do feedback de alerta } \\
\text { do sistema }\end{array}$ \\
\hline 21 & MC & & & É verdade! & $\begin{array}{l}\text { O jogador toca na peça cuja casa foi } \\
\text { iluminada pelo sistema }\end{array}$ \\
\hline 22 & MC & Ação_J_1 & Ação_S_1 & & A peça é capturada \\
\hline 23 & MC & Ação_J_2 & Ação_S_3 & & \\
\hline 24 & MC & & & Isso é ruim! & \\
\hline 25 & FF & & & Você não gosta dessa regra? & \\
\hline
\end{tabular}

De acordo com o padrão simples de interação o Jogador_2 (MC) esperava que o sistema iluminasse as casas disponíveis para deslocamento da peça que selecionara (Ação_S_2). Sem perceber o feedback do sistema na linha 18, o Jogador_2 (MC) insiste em selecionar a mesma peça sem sucesso e, novamente, o sistema ilumina outra casa para alertá-lo. Tendo sua expectativa novamente frustrada, na linha 19, o Jogador_2 (MC) seleciona a casa para onde pretende deslocar sua peça, supondo, talvez, que o sistema estava demorando a responder. Há, portanto, nessa passagem, três rupturas na interação (linhas 17, 18 e 19). Observe-se que só quando seu oponente (Jogador_1/FF) interpreta a Ação_S_4 (porque a percebe visualmente) e o avisa que deve capturar a sua peça é que MC (Jogador_2) muda a jogada e captura a peça do adversário (linhas $22 \mathrm{e}$ 23), restaurando o padrão de interação.

O Dado 1 mostra duas coisas importantes. Primeiro que há um conflito entre as regras do modelo conceitual adotado pelo Jogo de Damas (obrigatoriedade de captura) e o modelo conceitual usado pelo Jogador_2/MC (possibilidade de sopro), o que é corroborado pela sua fala contrariada na linha 24: "Isso é ruim!"”. O segundo aspecto tem a ver com o fato de o Jogador_2 (MC) não ter percebido o feedback oferecido pelo sistema (Ação_4_S), ainda que a casa da peça iluminada esteja na mesma linha da peça que ele tenta selecionar, o que, supostamente, facilitaria a sua percepção (Figura 1).

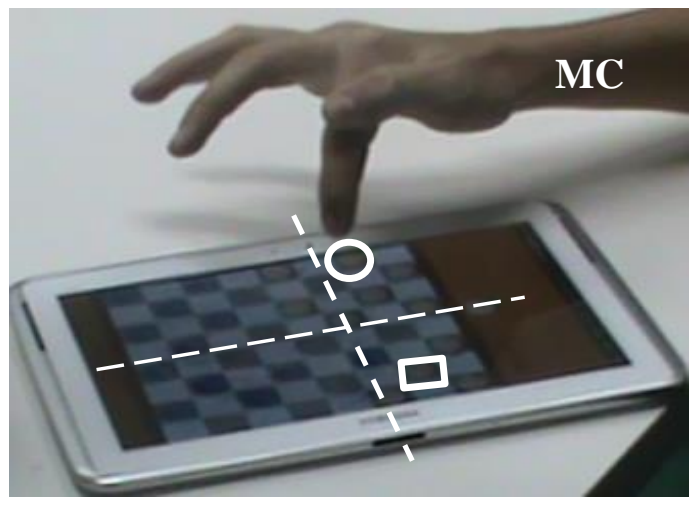

\section{Figura 1 - Imagem do tablet no momento em que MC tenta selecionar uma peça (círculo branco) e a interface ilumina a casa de outra peça (quadrado branco)}

É esperado, durante uma partida, que os jogadores se mantenham concentrados. Do ponto de vista neuropsicológico esse fenômeno pode ser explicado com base no conceito de atenção seletiva proposto por Luria (1979): a capacidade de dirigir a atenção para uma coisa e não para outra durante uma determinada atividade, o que implica a inibição de fatores que nela co-ocorrem (Coudry e Freire, 2005). O foco da 
atenção só muda quando um estímulo se apresenta de maneira suficientemente forte para deslocá-lo, passando de um estado de atenção arbitrária, orientado pelo próprio sujeito, para o de atenção não arbitrária, dirigido por algo externo que se impõe ao sujeito (Vygotsky, 2004). A iluminação da casa da peça do Jogador_2 (MC) não é forte o suficiente para operar essa mudança, o que poderia ser melhorado com uma iluminação mais contrastante ou, mesmo, com a sua associação a um som.

Assim, podemos dizer que, no caso do Dado 1, o conflito entre os modelos conceitual do sistema e do jogador, acrescido de um feedback visual pouco eficiente, impactam a usabilidade do Jogo de Damas. Esse fato é comprovado pela recorrência desse mesmo problema com o Jogador_2 (MC) na linha 67 (aproximadamente 2 minutos após a ocorrência do Dado 1) e com o Jogador_1 (FF) na linha 87 (aproximadamente 1 minuto depois de ocorrer pela segunda vez com MC).

Vejamos agora o Dado 2 (Tabela 6), que acontece entre as linhas 54 e 58 e é protagonizado desta vez pelo Jogador_1 (FF). Neste momento do jogo existem duas peças do Jogador_2 (MC) que podem ser capturadas em sequência.

Tabela 6 - Dado 2: Ações encadeadas do sistema

\begin{tabular}{|c|c|c|c|c|c|}
\hline $\mathbf{L}$ & $\mathbf{J}$ & Ações & Interface & Enun. & Observações \\
\hline 54 & FF & Ação_J_1 & 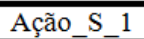 & & \\
\hline 55 & FF & Ação_J_2 & $\begin{array}{l}\text { Ação_S_3 } \\
\text { Ação_S_1 }\end{array}$ & & $\begin{array}{l}\text { Captura a peça do adversário seguida da iluminação da próxima } \\
\text { casa para onde a peça de FF deve ser deslocada de modo a } \\
\text { capturar a segunda peça de MC }\end{array}$ \\
\hline 56 & FF & Ação_J_1 & Ação_S_5 & & A casa iluminada na linha 55 retorna ao padrão não iluminado \\
\hline 57 & FF & Ação_J_1 & Ação_S_1 & & FF repete a mesma ação da linha 56 \\
\hline 58 & FF & Ação_J_2 & $\begin{array}{l}\text { Ação_S_3 } \\
\text { Ação_S_6 }\end{array}$ & & Captura a segunda peça do adversário e faz uma dama \\
\hline
\end{tabular}

Na linha 55 o sistema executa duas ações de forma encadeada: captura a peça do adversário e ilumina a casa que o Jogador_1 (FF) deve selecionar para capturar a próxima peça, dispensando, assim, a necessidade de o Jogador_1 (FF) ter que tocar mais uma vez em sua própria peça. Ocorre que o Jogador_1 (FF) aprendeu e, a essa altura, automatizou (Luria, 1979) pela repetição significativa, o padrão simples de interação (toca peça / ilumina casa / toca casa / desloca peça) e não consegue, rapidamente, compreender o feedback do sistema para adequar o seu movimento, dirigindo seu toque à casa e não à peça, razão pela qual, na linha 55, toca mais uma vez a peça. Dessa vez, é o sistema que tem a sua expectativa de interação quebrada, uma vez que esperava que o Jogador_1 (FF) executasse a Ação_J_2 e não a Ação_J_1 como faz, o que leva o sistema a apagar a casa que iluminara para reiniciar o padrão simples de interação. $\mathrm{Na}$ linha 57 o Jogador_1 (FF) se vê obrigado a repetir a Ação_J_1 para dar continuidade à interação.

O Dado 2 mostra um novo problema relacionado à usabilidade do sistema na linha 56. A Ação_S_5 também quebra a interação, tanto que o Jogador_1 (FF) se vê obrigado a repetir a Ação_J_1 (linha 57). Se o sistema respondesse à Ação_J_1 na linha 56 com a Ação_S_2, a interação teria sido mantida, em conformidade com o padrão simples de interação. A Ação_S_5, portanto, do nosso ponto de vista, é uma restrição desnecessária.

É interessante observar que essa mesma situação ocorrera com o este mesmo jogador (FF), antes mesmo da ocorrência do Dado 2 (linhas 39 e 41 do BDN), e ele não teve nenhum problema para compreender o encadeamento da Ação_S_3 + Ação_S_1, respondendo com a Ação_J_2; e novamente, depois do Dado 2, às linhas 62 a 64 do BDN. Essa oscilação no comportamento do Jogador_1 (FF) mostra que a interação usuário/interface não é regular e não se dá em linha contínua; como todo aprendizado está sujeito a idas e vindas (Vygostsky, 1991) provocadas por interferências contextuais. 


\subsection{Dados 3 e 4: Análise da interação por meio do tabuleiro}

O jogo com tabuleiro, como já foi dito, foi realizado após a interação via tablet e durou o dobro do tempo da partida anterior. No caso do tabuleiro não há respostas do "sistema" e a interação entre os jogadores se dá em função da configuração das peças a cada momento do jogo. Assim, o padrão de interação compreende duas ações básicas, uma destinada ao deslocamento da peça no tabuleiro e a outra destinada à captura de uma peça do adversário, que correspondem, cada uma delas, a um conjunto de movimentos:

Ação_J_1: jogador toca e arrasta a peça para deixá-la em uma determinada casa

Ação_J_2: jogador pega a peça, levanta-a por sobre a peça do adversário e a deixa na casa subsequente à casa do adversário

A ação complexa de capturar em sequência duas peças do usuário, no mundo real, não apresenta dificuldades porque, diferentemente do que ocorre no contexto digital, a peça do jogador permanece em suas mãos: a peça passa sobre a primeira peça do oponente, toca a casa subsequente, passa sobre a segunda peça e, finalmente repousa na casa subsequente. No caso da versão digital, após a captura da primeira peça o jogador visualiza a sua peça na casa subsequente - já que não pode mantê-la suspensa no espaço bidimensional - o que pode influenciar o toque sobre ela como fez o Jogador_1 (FF) no Dado 2. Assim, no tabuleiro, embora a captura em sequência corresponda a uma ação complexa, ela é natural (e simples), em termos de movimentos, na interação entre jogador e tabuleiro.

Desta partida destacamos a ocorrência dos Dados 3 (Tabela 7) e 4 (Tabela 8). No primeiro deles os jogadores alternam suas jogadas até que o Jogador_2 (MC) alerta o Jogador_1 (FF) sobre a existência de uma de suas peças em posição de captura.

Tabela 7 - Dado 3: O Jogador_2 (MC) "funciona" como o Jogo Damas Digital

\begin{tabular}{|c|c|l|l|l|}
\hline L & J & \multicolumn{1}{|c|}{ Ações } & \multicolumn{1}{|c|}{ Enunciados orais } & \multicolumn{1}{c|}{ Observações } \\
\hline 11 & FF & Ação_J_1 & & Peça fica no local deixado pelo jogador \\
\hline 12 & MC & Ação_J_1 & & Peça fica no local deixado pelo jogador \\
\hline 13 & MC & & Come! & Alerta FF sobre uma peça em posição de captura \\
\hline 14 & FF & Ação_J_2 & Ele é meu computador! & Captura peça do oponente \\
\hline
\end{tabular}

Na linha 13 o Jogador_2 (MC) diz "Come!", assumindo assim o papel da interface de DD ao iluminar a casa do jogador próxima a uma peça do adversário em posição de captura. Observe-se que essa função de alerta é reconhecida pelo Jogador_1 (FF) quando diz, à linha 14, "Ele é meu computador!". Coisa semelhante ocorre entre as linhas 64 a 72, Dado 4 (Tabela 8).

Tabela 8 - Dado 4: Regra do jogo no tabuleiro

\begin{tabular}{|c|c|c|l|l|}
\hline L & Jogador & Ação & \multicolumn{1}{|c|}{ Enunciados } & \multicolumn{1}{c|}{ Observaç̃es } \\
\hline 64 & FF & Ação J 1 & & Peça fica no local deixado pelo jogador \\
\hline 65 & MC & Ação J 1 & & Peça fica no local deixado pelo jogador \\
\hline 66 & FF & & Não vai comer? & \\
\hline 67 & MC & & Não! & \\
\hline 68 & FF & & No tabuleiro não é obrigatório? & \\
\hline 69 & MC & & Não posso comer para trás & Apontando a peça \\
\hline 70 & FF & & E a outra? & Referindo-se a uma peça próxima a da linha 69 \\
\hline 71 & MC & & & Volta a peça movida na linha 65 para onde estava \\
\hline 72 & MC & Ação_J_2 & & Captura peça do oponente \\
\hline
\end{tabular}


Dessa vez é o Jogador_1 (FF) quem assume o papel da interface e alerta o adversário para o fato de que ele pode subtrair uma de suas peças. Como o Jogador_2 (MC) se recusa a subtrair a peça em questão (linha 67), o Jogador_1 (FF) pergunta se no jogo com tabuleiro a regra de captura não é obrigatória. Nesse momento, o Jogador_2 (MC) aponta uma peça diferente daquela a qual o Jogador_1 (FF) se refere (linhas 69 e 70), dando mostras de que não havia percebido a peça que estava em posição de captura. Observamos que em uma partida informal, a interação verbal entre os jogadores é mais frequente no jogo com tabuleiro, como se as suas falas preenchessem o que é mostrado pela interface na sua versão digital.

Os Dados 3 e 4 mostram duas coisas interessantes. Primeiro que os jogadores que no jogo anterior tiveram que se ajustar às regras do DD, mesmo contrariados, como o Jogador_2 (MC) demonstrou (Isso é ruim! - linha 24 do Dado 1), ao usarem o jogo em tabuleiro, mantêm a obrigatoriedade de captura como regra. Segundo, observamos que na versão física o feedback de alerta de captura é substituído ou pela fala (que nem sempre é suficiente) ou pela fala acompanhada de gestos indicativos, o que mostra que o mapeamento de feedbacks efetivos para o contexto digital pode ser um processo complexo.

\section{CONSIDERAÇÕES FINAIS}

Neste estudo procuramos mostrar que a interação jogador/interface, vista como uma espécie de diálogo mapeado no sistema como ações dirigidas a objetivos específicos, pode ser produtiva para a identificação de problemas de usabilidade, beneficiada pelo uso do BDN como recurso metodológico. A realização do estudo de caso buscou, tanto quanto possível, se aproximar de uma partida de Damas real e informal entre dois jogadores, sem que houvesse uma tarefa previamente elaborada para que executassem. Nesse contexto, a interação verbal entre eles foi, também, fonte de dados e de análise.

No caso específico da dupla de jogadores observamos no Dado 1 a influência da adoção de uma regra diferente daquela representada no modelo conceitual da versão digital do jogo, gerando uma espécie de "mal-entendido" na interação entre o Jogador_2 (MC) e a interface, quando então pudemos identificar um problema de usabilidade. De forma semelhante, no Dado 2, observamos como o modelo de interação previsto pelo DD "sugere" ao Jogador_1 (FF) uma determinada resposta que não é interpretada corretamente, ocasião em que o sistema retorna a um padrão anterior de interação, o que também, na nossa análise, se configura como um problema de usabilidade. Os Dados 3 e 4 reafirmam o caráter dialógico da atividade de jogar e expõem o modo como os jogadores se portam naturalmente diante do tuleiro, muitas vezes deixando escapar uma situação de jogo que lhes é favorável.

O deslocamento de uma peça - quando o jogador toca uma peça e automaticamente o tabuleiro ilumina casas livres circunvizinhas - nos leva a pensar até que ponto o sistema deve antecipar decisões que na versão física são de responsabilidade do jogador. A transposição de jogos para o contexto digital, certamente, acrescenta características desejáveis, como as que observamos na versão digital do Damas: alteração da cor das peças e de escolha do grau de dificuldade; possibilidade de jogar contra o computador, verificação automática de erros, etc. No entanto, é preciso evitar excessos que, eventualmente, retiram das mãos do jogador o controle do jogo, destituindo da interação o que nela há de mais interessante: a construção online de estratégias visando antecipar e coibir a ação do adversário, convocando o funcionamento de processos mentais superiores.

\section{NOTAS DO TEXTO}


${ }^{1}$ Esses dados fazem parte de um estudo maior do qual participaram seis voluntários de diferentes faixas etárias e com diferentes graus de familiaridade com a tecnologia e com o Jogo de Damas. As duplas de jogadores foram formadas aleatoriamente, razão pela qual não consideramos a priori os efeitos que a faixa etária, a familiaridade com a tecnologia e com o jogo, podem exercer nos resultados. Esses fatores poderão ser melhor analisados por ocasião da análise de interação das três duplas de jogadores.

${ }^{2} \mathrm{O}$ BDN se desenvolve desde 1996 no interior do Projeto Neurolinguística Discursiva: afasia e infância, coordenado pela Profa Coudry (CNPq 312522/2013-4), objetivando a transcrição, o armazenamento e a busca de dados que são produzidos nas sessões do Centro de Convivência de Afásicos (CCA) e do Centro de Convivência em Linguagens (CCazinho), ambos do Instituto de Estudos da Linguagem da UNICAMP, frequentados por sujeitos que apresentam dificuldades linguísticas (de fala, leitura e escrita) e/ou cognitivas (atenção, raciocínio, gestualidade, etc).

\section{REFERÊNCIAS BIBLIOGRÁFICAS}

ALTY, J.; MCCARTNEY, C.; Design of a multi-media presentation system for a process control environment. In: EUROGRAPHICS MULTIMEDIA WORKSHOP, Session 8: Systems, 1991, Stockholm, Suecia, 1991.

COUDRY, M. I. H.; Registro de linguagem, gestos e percepção no Banco de Dados em Neurolinguística. In: 51º SEMINÁRIOS DO GEL. Taubaté, SP. 2003.

COUDRY, M. I. H.; FREIRE, F. M. P. O trabalho do cérebro e da linguagem: a vida e a sala de aula. Campinas, SP; Brasília/DF: CEFIEL-UNICAMP/MEC, 2005. 64p.

FREIRE, F. M. P. A aplicação do BDN em práticas discursivas a distância. In: ESTUDOS LINGUÍSTICOS XXXIII, Taubaté, SP, 2004. p. 152-157, 2004.

FREIRE, F. M. P. Agenda Mágica: linguagem e memória. Campinas: UNICAMP/IEL, 2005. Tese de Doutorado.

FREIRE, F. M. P. Enunciação e Discurso: a linguagem de programação Logo no discurso do afásico. Campinas: Mercado de Letras, 2006. [1999] 255p .

JOHNSON, J.; HENDERSON, A. Conceptual Models: begin by designing what to design. Interations, Nova Iorque, v.9, n.1, p. 25-32, 2002.

LURIA, A. Curso de Psicologia Geral. Rio de Janeiro: Civilização Brasileira, 1979.

NIELSEN, J. Usability Engineering. EUA: Morgan Kaufmann, 1993, 362 p.

SILVA, A. C. Interação Multimodal em Ambientes de EaD: proposta de arquitetura e impactos. Campinas: UNICAMP/IC, 2014. Tese de Doutorado.

VYGOTSKY, L. S. A Formação Social da Mente. São Paulo, SP: Martins Fontes. 1991 [1960].

VYGOTSKY, L. S. Psicologia Pedagógica. São Paulo: Martins Fontes, 2004 [1926]. 